\title{
René Drucker Colín. In memoriam
}

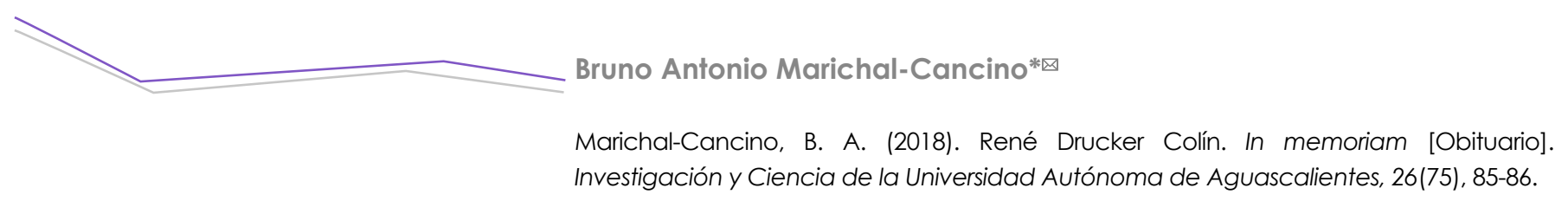

Durante miles de años, el humano se ha cuestionado sobre la función adaptativa del sueño. Y es que para todos los animales (y quizá hasta para las plantas) llega el momento en que todos disminuimos nuestro metabolismo y la actividad celular de forma circadiana. Muchas especulaciones han sido propuestas para intentar explicar la utilidad biológica del sueño (e.g., para recuperar el gasto energético empleado durante la vigilia, permitir a los centros de integración procesar toda la información recibida y generar los cambios estructurales correspondientes, la reestructuración del sistema inmune, etc.). Pero muy pocos han convertido en una misión para su vida el hecho de encontrar las evidencias empíricas que sustenten sus ideas.

Uno de los pioneros mundiales en el estudio empírico de la Neurobiología del sueño fue el Dr. René Raúl Drucker Colín. Sus aportaciones científicas en la Neurobiología del sueño fueron sustanciales para su época. El Dr. Drucker siempre mostró un ingenio que lo ponía por delante de sus contemporáneos. Por ejemplo, en una serie de estudios a finales de la década de los 60 y principios de la de los 70 adaptó un protocolo a base de cánulas para la extracción de líquido cerebroespinal proveniente de gatos en libre movimiento bajo diferentes condiciones (e.g., durante vigilia, durante sueño de ondas lentas, sueño de movimientos oculares rápidos, etc.). El líquido cerebroespinal obtenido de gatos restringidos de sueño o dormidos se inyectaba luego a gatos despiertos y el resultado fue impresionante: los gatos en vigilia caían en un profundo sueño poco tiempo después de la administración. Múltiples resultados reportados por el Dr. Drucker y sus colaboradores permitieron abrir decenas de líneas de investigación

\footnotetext{
* Departamento de Fisiología y Farmacología, Centro de Ciencias Básicas, Universidad Autónoma de Aguascalientes. Av. Universidad 940, Ciudad Universitaria, C. P. 20131, Aguascalientes, Ags., México. Correo electrónico: bruno.marichal@edu.uaa.mx

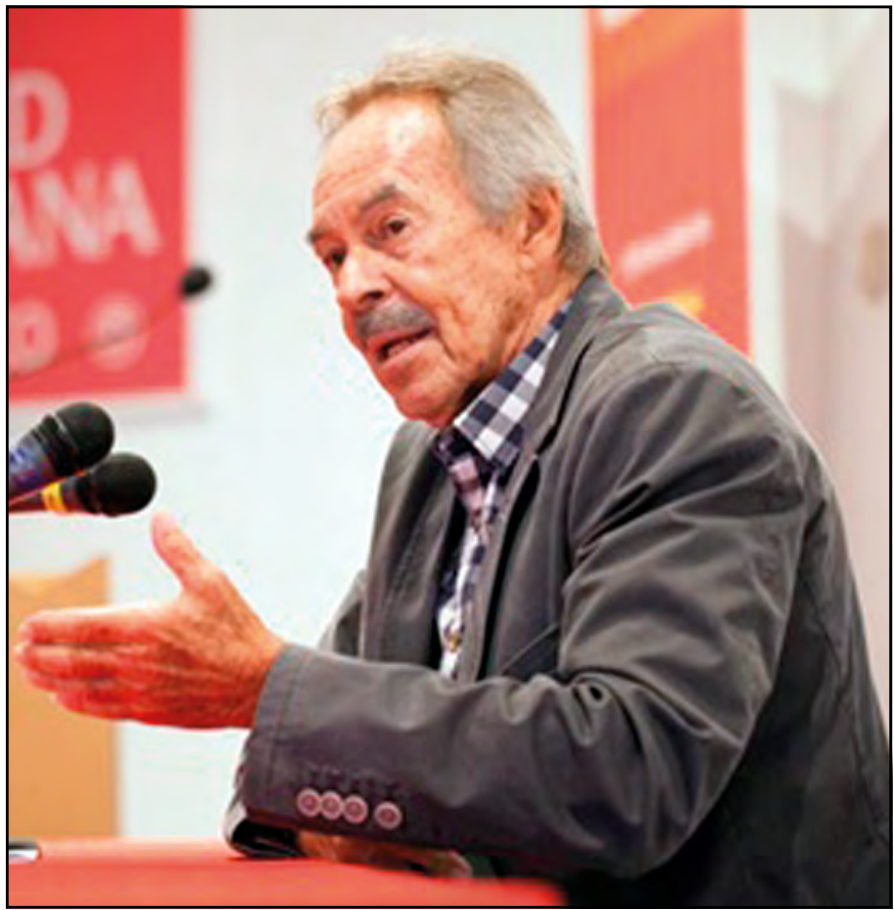

René Drucker Colín (1937-2017). Pionero a nivel mundial en el estudio de la Neurobiología del sueño y divulgador incansable. Fotografía de Mario Hernández.

para comprender la participación de hormonas y neurotransmisores en las diferentes etapas del sueño. Se involucró también en otros temas como la enfermedad de Parkinson, las células madre, la marihuana, pero su mayor aportación se realizó en la neurobiología del sueño.

El Dr. Drucker nació en la Ciudad de México en 1937. Se tituló como psicólogo por la Universidad Nacional Autónoma de México (UNAM) y continuó sus estudios de posgrado en EE. UU. y en Canadá. Fue miembro emérito del Sistema Nacional de Investigadores, presidente de la Asociación Mexicana de la Ciencia y ocupó múltiples puestos directivos relacionados con la ciencia y el posgrado 
en la UNAM. Recibió numerosos premios por su destacada carrera (e.g., Premio Nacional de Ciencias y Artes). Del Dr. René Drucker podemos apreciar una segunda faceta como extraordinario divulgador de la ciencia. Ya para el final de su carrera, el Dr. René Drucker comenzó a participar, sin abandonar sus investigaciones, en aspectos políticos, siempre de la mano de la ciencia y la tecnología. Perteneció, por ejemplo, al Consejo Consultivo de Ciencias de la Presidencia de la República. El pasado 17 de septiembre de 2017 murió a los 80 años en la Ciudad de México.

Cuando uno recuerda la trayectoria académica de grandes personajes de la ciencia, como lo fue el Dr. Drucker, queda de manifiesto que poco o muy poco puede ser alcanzado en esta vida sin un inescrutable sentido de compromiso y rectitud con la profesión. Recordando a un gigante sin tiempo, otro René, Descartes: "..las almas más grandes son capaces de los mayores vicios, como de las mayores virtudes; y los que andan muy despacio pueden llegar mucho más lejos, si van siempre por el camino recto, que aquellos que corren, pero se apartan de él..".

Aprendamos de los grandes todo lo que, según nuestro más lúcido criterio, sea meritorio de ser aprendido y replicado. Trabajemos siempre por el camino recto para que nuestro paso por este planeta sea más benéfico que perjudicial para todos los que en él habitamos (humanos y no humanos).

Descanse en paz el Dr. René Raúl Drucker Colín.

\section{REFERENCIAS}

- Hernández, M. (3 de septiembre de 2014). La ciencia en México aún no demuestra su importancia [Fotografía ilustrativa de blog]. Recuperada de https://prendecientifico. wordpress.com/2014/09/03/la-ciencia-aun-no-demuestra-suimportancia/\#more-3 